\title{
PREFACE TO THE SECOND EDITION
}

When I completed the first edition of The Politics of Accommodation in 1967, there were already many signs that Dutch politics was changing in a number of important respects. Therefore, I included a chapter called "Dutch Politics in Transition," in which I called attention to the fact that in the 1960's the social cleavages had gradually become less deep and less relevant to the political process, that popular deference and allegiance to the leadership of the religious-ideological blocs was declining, and that elite control appeared to become less firm and confident. In particular, I pointed out that the support for the major parties that together managed the system of accommodation was lower in the 1967 parliamentary elections than ever before-I called this a "clear warning" to the political leaders-and I characterized the year 1966 with its turbulent events that were to a large extent provoked by errors of leadership as "not a year of pride for the politics of accom- 
modation." I also emphasized, however, that it was my intention to analyze the general pattern of Dutch politics as it had operated since 1917 rather than to focus on the 1960 s, and that if the latter objective had been consistently pursued, most of the statements would have had to be amended with the qualifying remark, "but the situation may now be changing."

It is now clear that the developments of the mid-1960's were merely the beginning of rapid and far-reaching changes that challenged the very foundations of the politics of accommodation. In fact, with the advantage of hindsight, I now think that the politics of accommodation in the Netherlands came to an end around 1967. The revolutionary changes since then are analyzed in this second edition in a new Chapter X, "The Breakdown of the Politics of Accommodation," which replaces the discussion in the old chapter on "Dutch Politics in Transition." The other chapters are reprinted without change but should now, for the most part, be read in the past tense.

Although for the Netherlands the politics of accommodation has largely become history, it retains its theoretical value as a source of constructive amendments to pluralist theory, its empirical value as an explanation of the pattern of Dutch democracy in the 1917-1967 period, and its practical value as a normative model that is more appropriate than the pluralistic model for the world's many highly divided societies aspiring to democratic rule. Finally, as I shall attempt to show in Chapter $\mathrm{X}$, the recent upheavals in Dutch politics can be understood only in terms of the tensions that were inherent in the politics of accommodation.

Leyden, The Netherlands

A.L.

June 1974 